\title{
Targeted Tumor Killing via an Intracellular Antibody against erbB-2
}

\author{
Jessy Deshane, * Gene P. Siegal, ${ }^{\ddagger}$ Ronald D. Alvarez, ${ }^{\S}$ Ming H. Wang, * Meizhen Feng, * Gustavo Cabrera, * Tiepu Liu," \\ Mark Kay,' and David T. Curiel* \\ *Gene Therapy Program, University of Alabama at Birmingham; ${ }^{\ddagger}$ Departments of Pathology, Cell Biology, and Surgery, University of \\ Alabama at Birmingham; ${ }^{\S}$ Department of Gynecologic Oncology, "Biostatistics Unit, Comprehensive Cancer Center, University of \\ Alabama at Birmingham, Birmingham, Alabama 35294; and 'University of Washington, Division of Medical Genetics, Seattle, \\ Washington 98195
}

\begin{abstract}
Specific killing of erbB-2-overexpressing tumor cells can be achieved using expression of an intracellular antibody directed against the erbB-2 oncoprotein. We have developed a strategy using a recombinant adenovirus encoding an anti-erbB-2 single chain antibody to achieve targeted tumor cell killing in vivo and can show significantly prolonged survival of animals carrying a human ovarian carcinoma tumor burden within their peritoneal cavities. This strategy of gene therapy for ovarian carcinoma offers the potential to achieve highly specific, targeted killing of human tumor cells and thus establishes the rationale to undertake human clinical trials on this basis. (J. Clin. Invest. 1995. 96:29802989.) Key words: ovarian carcinoma $\cdot$ erbB-2 $\bullet \mathrm{sFv} \cdot$ gene therapy $\bullet$ antibody
\end{abstract}

\section{Introduction}

Strategies have been developed to accomplish gene therapy for cancer based upon specific correction of the genetic lesions associated with neoplastic transformation. In this regard, methods have been proposed to achieve the augmentation of tumor suppressor genes which have undergone mutational inactivation by replacement of their wild-type antioncogene function (14). In addition, specific approaches have been developed to accomplish targeted abrogation of overexpressed dominant oncoproteins. These approaches have been based largely upon the employment of antisense methods to achieve selected knockout of a target oncoprotein at the transcriptional $(5,6)$ or posttranscriptional level (7-9).

As an alternate means to achieve abrogation of transforming oncogenes, we have developed a method based upon expression

Address correspondence to David T. Curiel, M.D., Director, Gene Therapy Program, University of Alabama at Birmingham, 1824 6th Avenue South, Room WTI 620, Birmingham, AL 35294. Phone: 205-934-8627; FAX: 205-975-7476.

Received for publication 15 August 1995 and accepted in revised form 13 September 1995.

J. Clin. Invest.

(C) The American Society for Clinical Investigation, Inc.

$0021-9738 / 95 / 12 / 2980 / 10 \quad \$ 2.00$

Volume 96, December 1995, 2980-2989 of an intracellular single-chain antibody ( $\mathrm{sFv}$ ) directed against the target oncoprotein (10). In the context of the erbB-2 tyrosine kinase receptor, we have demonstrated that $\mathrm{sFv}$-mediated entrapment at the level of the endoplasmic reticulum (ER) ${ }^{1}$ can trigger cellular apoptosis (11). Importantly, this effect is accomplished selectively in erbB-2-overexpressing tumor targets; the viability of non-erbB-2-expressing cells is not affected by this genetic intervention $(11,12)$. This approach thus represents a novel genetic means to accomplish a highly selective, targeted tumor cell killing.

In this report, we have further explored the utility of this gene therapy strategy in ovarian carcinoma. We show here that delivery of an anti-erbB-2 sFv gene offers an approach which allows selective tumor cell killing, with a therapeutic outcome, in a murine model of human ovarian carcinoma. These promising findings provide the rationale to undertake human clinical trials.

\section{Methods}

Cell lines. The human ovarian carcinoma cell line SKOV3. ip1, an SKOV3 derivative cell line, was kindly provided by Janet Price (Baylor University, Houston, TX). This cell line was maintained in DME/F12 media supplemented with $10 \%$ heat-inactivated FCS (PAA, Linz, Austria), L-glutamine ( $200 \mu \mathrm{g} / \mathrm{ml})$, penicillin $(100 \mathrm{U} / \mathrm{ml})$, and streptomy$\operatorname{cin}(25 \mu \mathrm{g} / \mathrm{ml})$ at $37^{\circ} \mathrm{C}$, in a humidified $5 \% \mathrm{CO}_{2}$ atmosphere.

Determination of an optimum vector for in vivo transduction. $10^{7}$ SKOV3. ip1 cells were transplanted orthotopically into athymic nude mice by the intraperitoneal route. $48 \mathrm{~h}$ after transplantation, animals were challenged with vectors encoding an Escherichia coli $\beta$-galactosidase reporter gene (LacZ). Animals (seven per group) received 100 pfu/cell of AdCMVLacZ, AdpL complex containing a LacZ-encoding plasmid $\mathrm{pCMV} \beta$, or DOTAP-DNA complexes containing $\mathrm{pCMV} \beta$. Preparation of AdpL complexes and DOTAP-DNA complexes has been described elsewhere $(11,13,14)$. Peritoneal lavage was performed 48 $\mathrm{h}$ later to harvest the tumor cells. Red blood cells were lysed with the ACK lysis buffer $\left(0.15 \mathrm{M} \mathrm{NH}_{4} \mathrm{Cl}, 1.0 \mathrm{mM} \mathrm{KHCO}_{3}, 0.1 \mathrm{mM} \mathrm{Na}_{2}\right.$ EDTA, $\mathrm{pH}$ 7.4). Lysis was terminated by the addition of $5 \mathrm{ml}$ of complete media. The tumor cells were then analyzed by FACS $^{\circledR}$ for reporter gene-transduced cells.

Briefly, $10^{6}$ tumor cells were incubated with biotinylated polyclonal anti-erbB-2 antibody (Dako Corp., Carpinteria, CA) for $30 \mathrm{~min}$ at room temperature. Cells were then washed $(3 \times 20 \mathrm{~min})$ with PBS $(\mathrm{pH}$

1. Abbreviations used in this paper: ER, endoplasmic reticulum; HSVTk, herpes simplex virus thymidine kinase. 
A

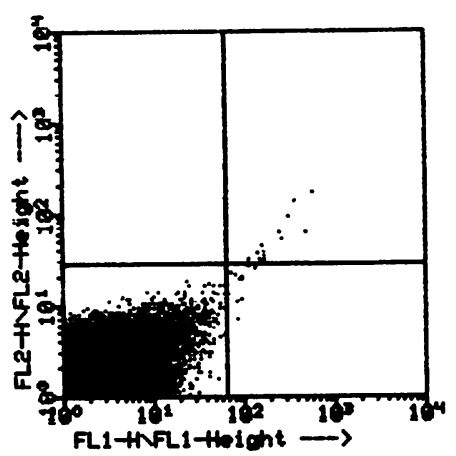

C

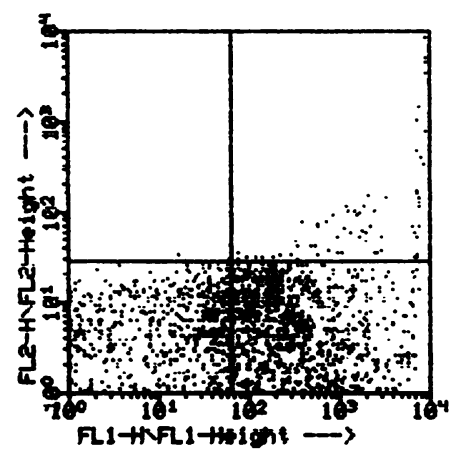

B

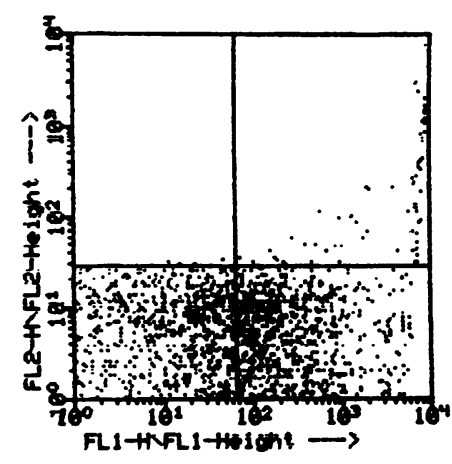

D

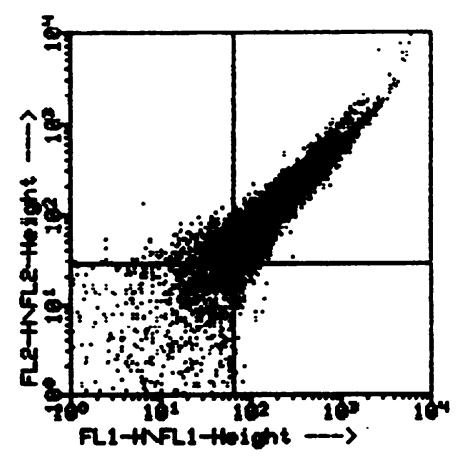

Figure 1. Determination of optimal vector strategy to accomplish in situ transduction of tumor cells localized in the peritoneum. Various vectors encoding the $E$. coli $\beta$-galactosidase reporter gene (LacZ) were delivered by the intraperitoneal route to athymic nude mice xenografted $48 \mathrm{~h}$ previously with the human ovarian carcinoma cell line SKOV3. ip1. Evaluated vectors included a E1A/B-deleted replication incompetent adenovirus, AdCMVLacZ; adenovirus-polylysine-DNA complexes containing the LacZ-encoding plasmid $\mathrm{pCMV} \beta$ and DOTAP-DNA complexes, also containing the plasmid $\mathrm{pCMV} \beta$. After transduction $(48 \mathrm{~h})$ animals underwent lavage to harvest peritoneal cells, which were then sorted by FACS $^{\circledR}$ for cell surface erbB-2 and LacZ expression. Experimental groups included: $A$, no vector transduction; $B$, DOTAP-DNA complexes; $C$, adenovirus-polylysine-DNA complexes; $D$, recombinant adenovirus.
7.4) and incubated with streptavidin-phycoerythrin (kindly provided by Dr. Pat Bucy, University of Alabama at Birmingham). Cells were washed again with PBS and resuspended in staining media $(10 \mathrm{mM}$ Hepes and 4\% FCS in PBS) in a 6-ml FACS ${ }^{\circledR}$ tube (Falcon, Franklin Lakes, NJ) and warmed at $37^{\circ} \mathrm{C}$ for $10 \mathrm{~min}$. Prewarmed $2 \mathrm{mM}$ fluorescein-di-galactoside (FDG) $(100 \mu \mathrm{l})$ was added, and the cells were incubated at $37^{\circ} \mathrm{C}$ for exactly $1 \mathrm{~min}$. FDG loading was stopped by the addition of $1 \mathrm{ml}$ of cold staining media. Cells were kept on ice and in the dark until analysis was completed. 10,000 cells were size-sorted first and then sorted for erbB-2-positive and LacZ-positive cells.

In vitro efficacy of the recombinant adenovirus encoding anti$e r b B-2 s F v$. A replication-incompetent, E1-deleted recombinant adenovirus encoding the ER form of the anti-erbB-2 sFv gene was constructed using homologous recombination techniques (15). This methodology has been described elsewhere $(16,17)$. SKOV3. ip1, a human ovarian carcinoma cell line overexpressing erbB-2, and HeLa, an erbB-2-nonexpressing human cervical carcinoma cell line, were plated at a density of 5,000 cells/well in a 96-well plate. Viral infections were carried out in DME media containing $2 \%$ FCS and were allowed to proceed at $37^{\circ} \mathrm{C}$ for $1 \mathrm{~h}$, after which time complete media were added to each well. Infection was carried at an moi of $2.5 \times 10^{6} \mathrm{pfu}(500 \mathrm{pfu} / \mathrm{cell}) .96 \mathrm{~h}$ after adenoviral infection, cells were analyzed for cell viability by the XTT assay (11). A control adenoviral vector, AdCMVLacZ, was used as a negative control. The XTT assay is based on the ability of viable cells alone to reduce XTT (2,3-bis [2-methoxy 4-nitro-5 sulfophenyl]2$\mathrm{H}$ tetrazolium-carboxanilide salt) to a colored product which can be read spectrophotometrically. At $96 \mathrm{~h}$ after infection, the supernatant was removed, and $50 \mu \mathrm{l}$ of solution containing $1.0 \mathrm{mg} / \mathrm{ml}$ of XTT, 0.0075 $\mathrm{mg} / \mathrm{ml}$ phenazine methasulfate, and $50 \mu \mathrm{l}$ RPMI medium was added to each well. After $30 \mathrm{~min}$, the reduction product was measured at $\mathrm{A}_{450}$ and compared with a standardized curve to determine the number of viable cells. Tumor cells were also analyzed for cell surface levels of erbB-2 using a polyclonal anti-erbB-2 antibody in combination with ABC-immunoperoxidase detection system (Dako Corp.).

In vivo efficacy of the recombinant adenovirus encoding anti$e r b B-2 s F v .2 \times 10^{7}$ SKOV3. ip1 cells were transplanted intraperitoneally into athymic nude mice, and tumor cells were harvested by peritoneal lavage after intraperitoneal administration of Ad21 (500 pfu/cell)

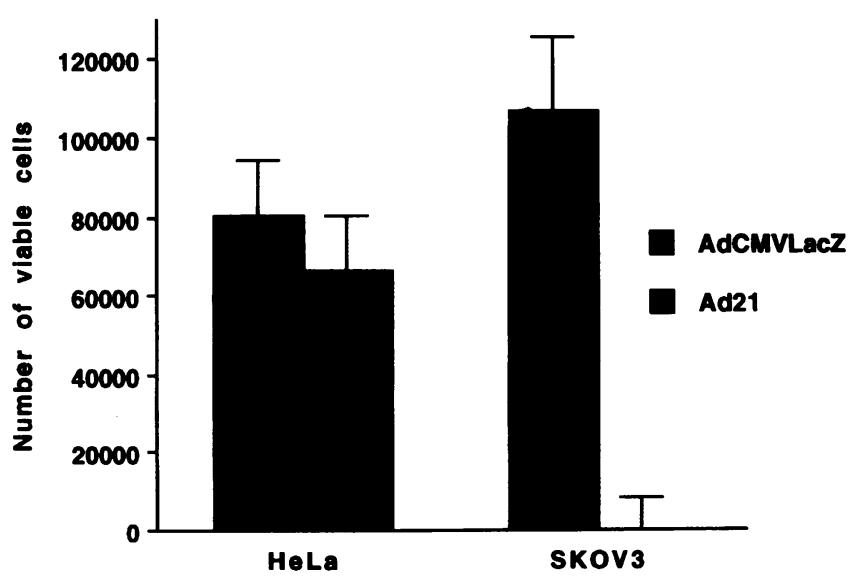

Figure 2. Analysis of cell viability. Transduced cells were evaluated for viability using the XTT assay at $96 \mathrm{~h}$ after transduction. Target cells included the erbB-2-negative cervical carcinoma cell line, HeLa, and the erbB-2-positive ovarian carcinoma cell line, SKOV3. ip1. 

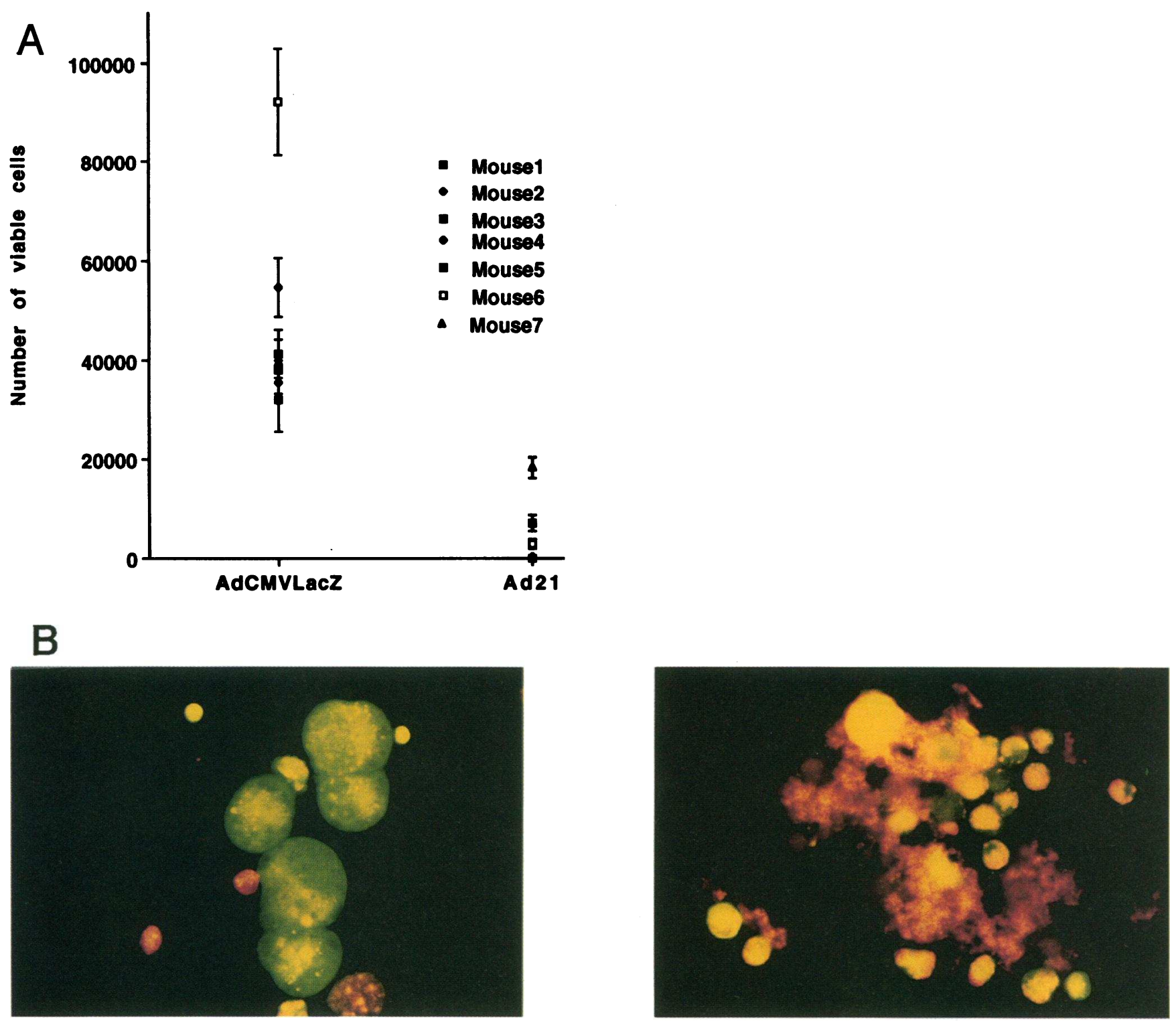

\section{AdCMVLacZ}

Ad21

Figure 3. Phenotypic consequences of in vivo transduction of tumor cells mediated by anti-erbB-2 encoding adenovirus Ad21. The erbB-2-positive ovarian cancer cell line SKOV3. ip1 was established orthotopically in athymic nude mice as a model of human ovarian carcinoma. After $48 \mathrm{~h}$, animals were treated by intraperitoneal administration of the reporter gene encoding recombinant adenovirus AdCMVLacZ or the anti-erbB-2 sFv encoding adenovirus Ad21. Tumor cells harvested by lavage were then analyzed for $(A)$ viability using the XTT assay or $(B)$ apoptosis using differential nuclear dye uptake. $\times 400$.

and analyzed for any phenotypic effect, secondary to the anti-erbB-2 gene transfer and expression. In situ lavage-harvested tumor cells from seven animals per group were evaluated for cell viability using the XTT assay (11). To determine whether the recombinant adenovirus encoding the anti-erbB-2 sFv induced apoptosis in vivo, cells were analyzed for changes indicative of programmed cell death. Briefly, a cell suspension was made at a density of $5 \times 10^{5}$ cells in the appropriate medium. 25 $\mu \mathrm{l}$ of the cell suspension was combined with $1 \mu \mathrm{l}$ of dye containing $100 \mu \mathrm{g} / \mathrm{ml}$ acridine orange $+100 \mathrm{mg} / \mathrm{ml}$ ethidium bromide. Cells were stained with this mixture and examined by fluorescent microscopy for apoptosis as demonstrated by aberrant chromatin organization.
In vivo treatment model. $2 \times 10^{7}$ SKOV3. ip1 cells were injected intraperitoneally into six SCID (CB-17) mice. $48 \mathrm{~h}$ after injection, two mice were challenged with an moi of $2 \times 10^{9}$ viral particles of control adenovirus (AdCMVLacZ) and two mice received the same dose of Ad21. At $14 \mathrm{~d}$ after treatment, animals were anesthetized with ketamine/ xylazine ( $10 \mathrm{mg}+15 \mathrm{mg} / 100$ grams, respectively) and killed by direct cervical dislocation. All six animals underwent complete autopsy at the same time, in succession, and microscopic examination was performed. For survival analysis, $3 \times 10^{7}$ cells were injected intraperitoneally into CB-17 SCID mice. Animals were challenged 5 d later with AdCMVLacZ or Ad21 at $500 \mathrm{pfu} /$ cell $(n=10)$. One control group re- 

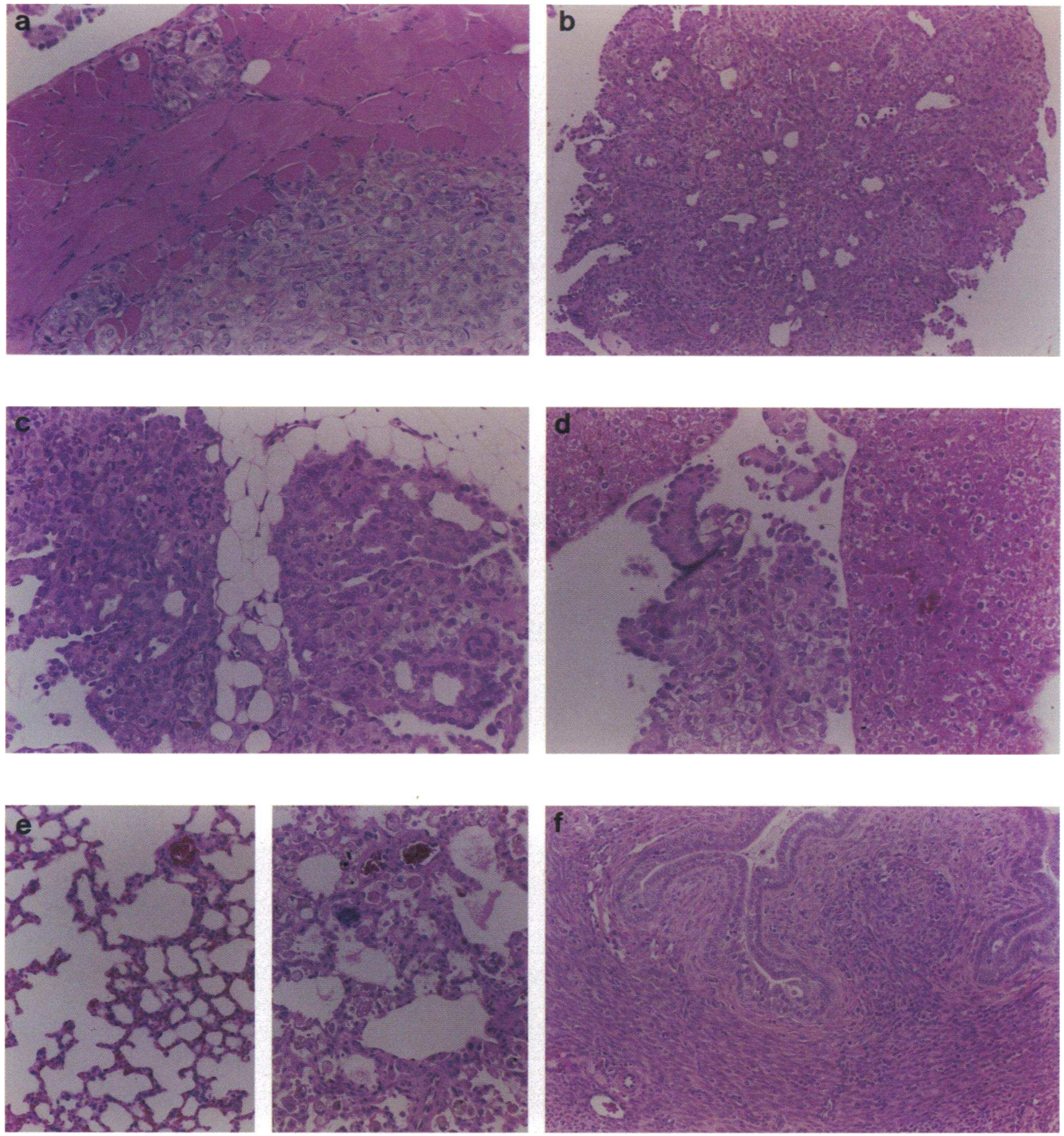

Figure 4. Antitumor efficacy of anti-erbB-2 sFv encoding adenovirus. CB-17 SCID mice were orthotopically xenografted with $2 \times 10^{7}$ SKOV3. ip1 cells and challenged after $48 \mathrm{~h}$ with either the reporter gene encoding adenovirus AdCMVLacZ or the anti-erbB-2 sFv encoding adenovirus Ad21. An additional control group received no vector administration. $A$ shows representative photomicrographs of control mice receiving no vector. (a) Tumor seen invading into and through abdominal wall musculature. (b) Ovarian carcinoma growing within the peritoneal cavity. (c) Tumor invading perirenal fat. Note attempt at gland formation by malignant cells. $(d)$ Tumor abutting, but not invading the liver parenchyma. $(e) L e f t$, normal lung parenchyma with minimal congestion; right, lung field from another animal with evident pigmented macrophages, interstitial expansion, and focal desquamation. $(f)$ Cross section through the uterine wall. $B$ shows representative photomicrographs of mice treated with $2 \times 10^{9}$ viral particles of AdCMVLacZ. ( $a$ ) Ovarian tumor seen attaching to thin strips of peritoneal lining (top). (b) Ovarian carcinoma growing within blood vessels. Note loss of normal vascular wall and rare RBCs in the lumen. (c) Ovarian tumor seen invading into the liver parenchyma. (d) Lowpower photomicrograph demonstrating normal fallopian tube, uterus, and ovary. (e) Pancreas with prominent central islet of Langerhans. No tumor is present. $(f)$ Normal renal cortex. $C$ shows histologic photomicrographs of representative organs and tissue from mice treated with $2 \times 10^{9}$ viral particles of Ad21. (a) Ovarian tumor in peripancreatic space. (b) No tumor is seen in the perirenal fat. Note the presence of a small amount of fat necrosis. $(c)$ Lung parenchyma with mild congestion. $(d)$ Calcific pericarditis. $(e)$ Unremarkable murine ovary and fallopian tube. Note prominent ovarian follicles. $(f)$ Mammary gland with normal histomorphology. 
B
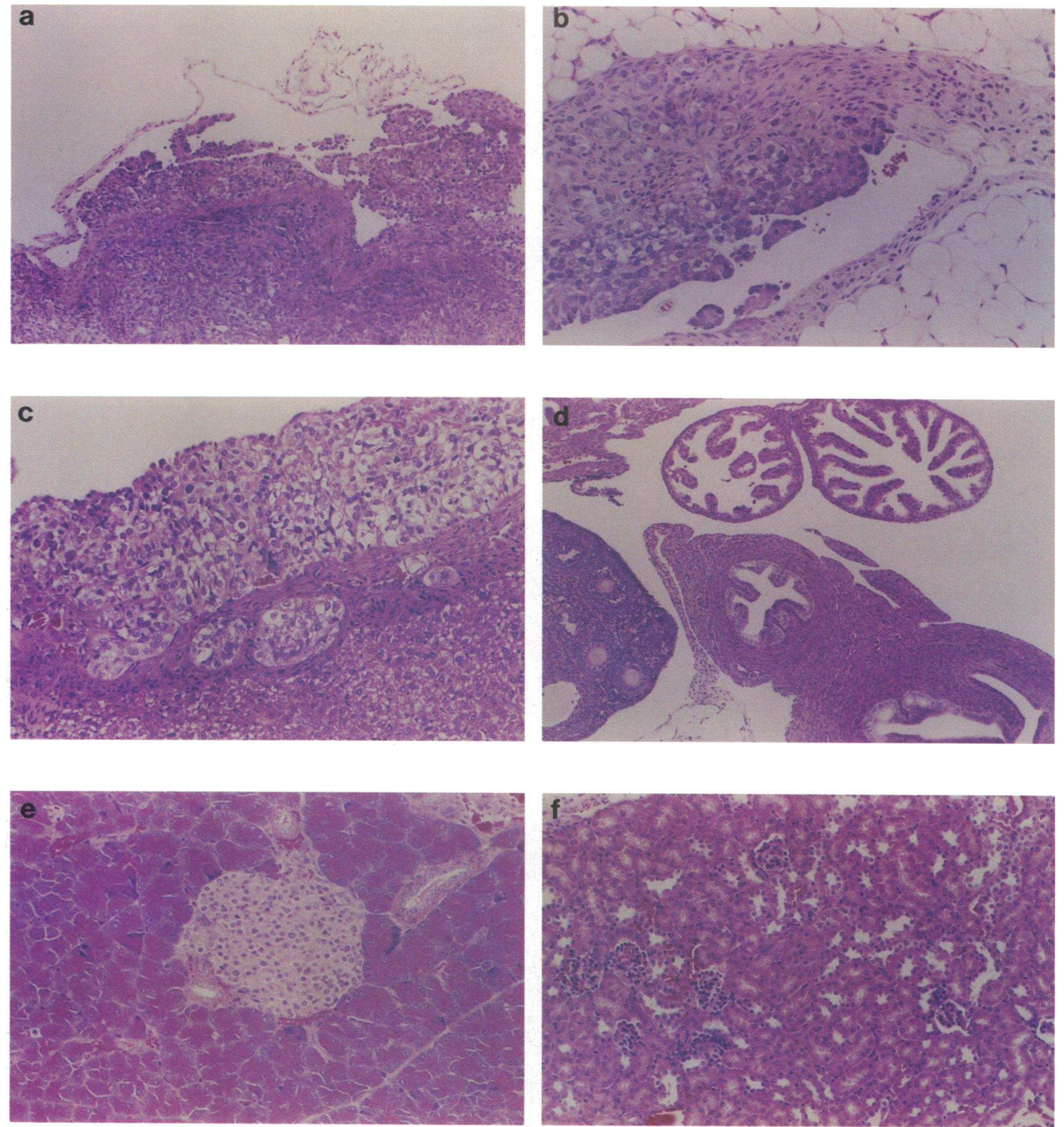

Figure 4 (Continued)

ceived only tumor cells and one additional group received only the recombinant adenovirus which served as an additional control group. Animals were assayed for survival. Statistical analysis was performed at day 36. Survival experience between control and experimental groups was compared, and statistical significance of difference was performed through the use of the log-rank test. To estimate the relative risks of death comparing control groups with the experimental group, a proportional hazards model was used.

\section{Results}

Advanced ovarian cancer is characterized by local dissemination of neoplastic cells within the peritoneal cavity. As most 


\section{C}
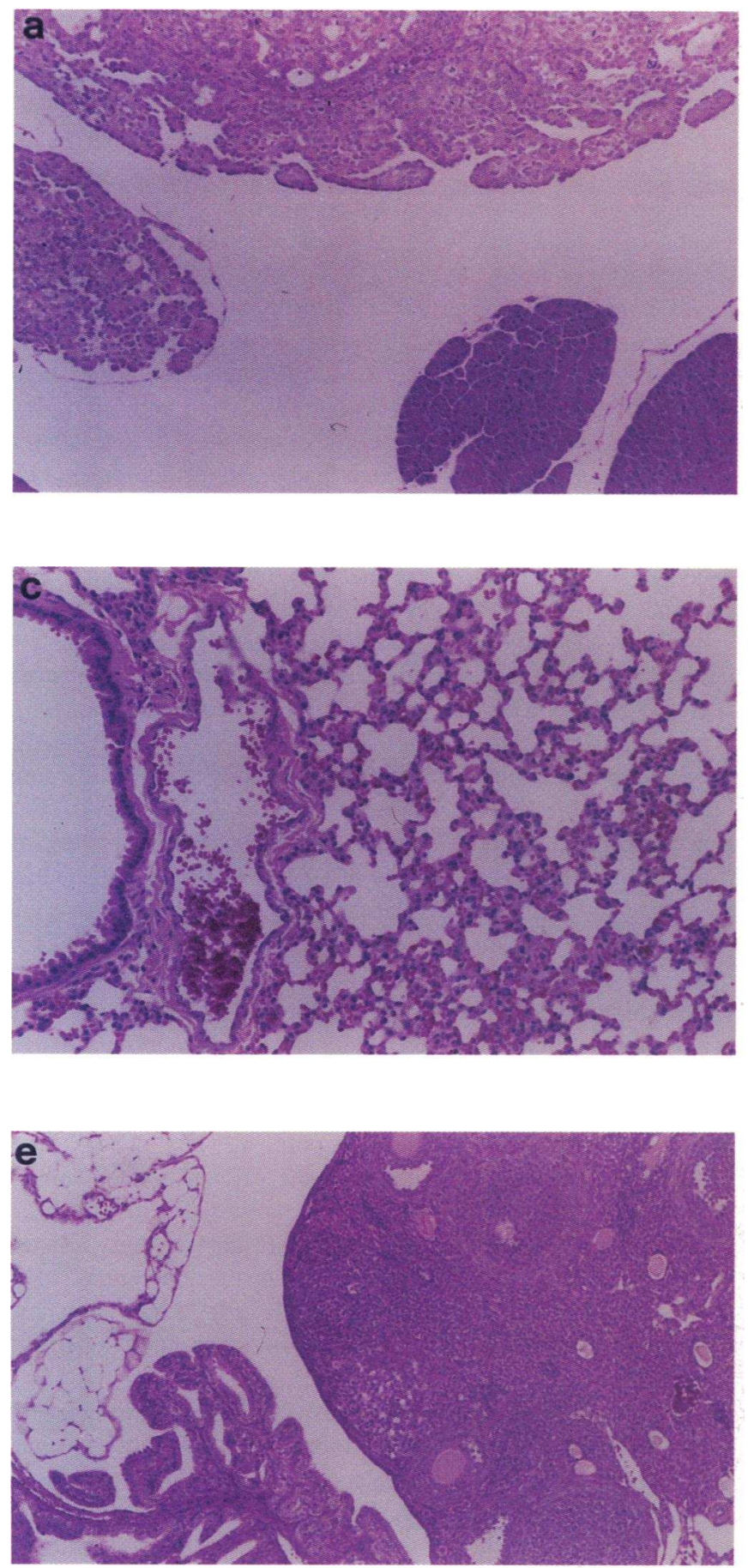
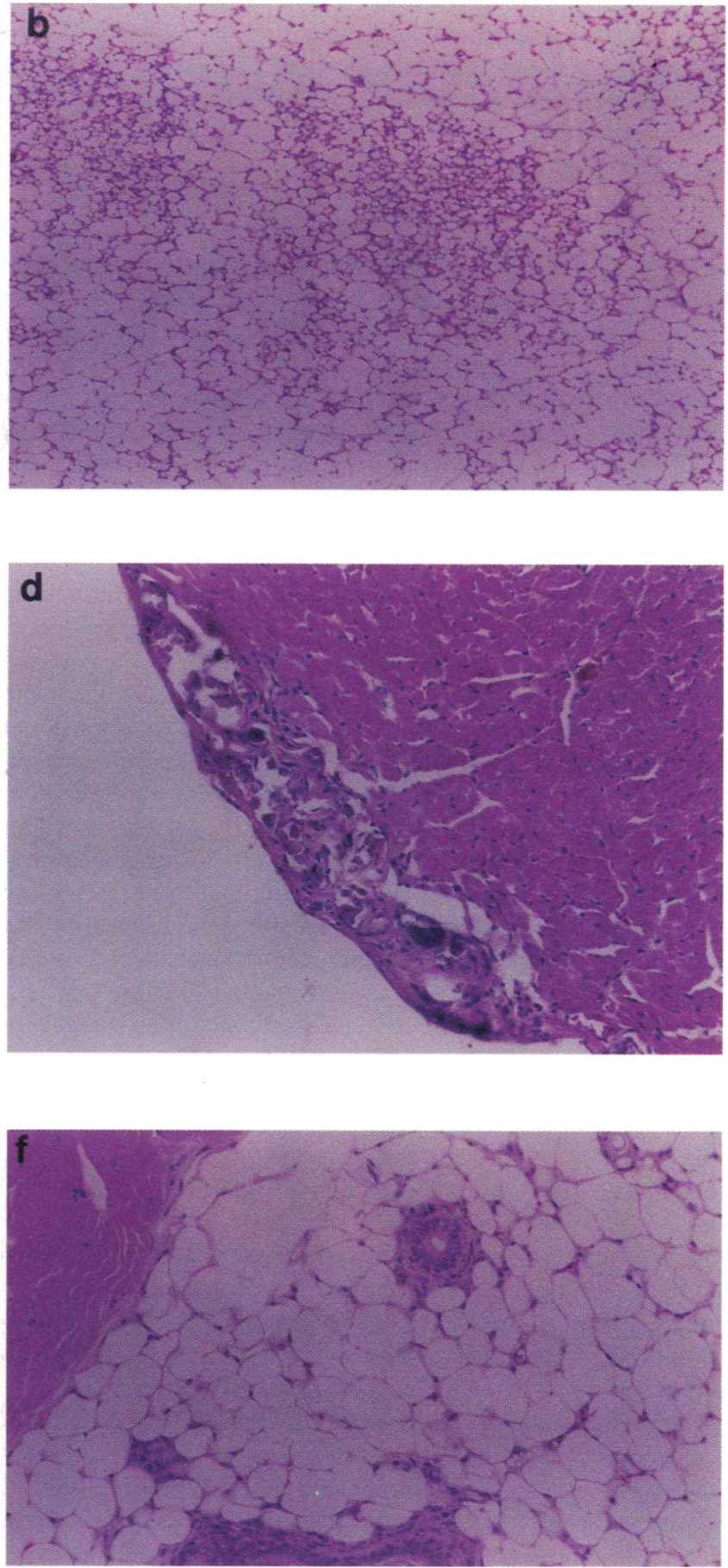

Figure 4 (Continued)

patients first present with nonlocalized disease, gene therapy strategies must accomplish in vivo transduction of tumor cells in situ within the peritoneum. Previously proposed gene therapy protocols for carcinoma of the ovary have approached this problem by either intraperitoneal administration of an allogenic toxin gene encoding ovarian cancer cells or murine packaging cells expressing herpes simplex virus thymidine kinase (HSVTk) encoding amphotrophic retrovirus (18). We have proposed using a strategy to achieve selective cytotoxicity in erbB-2-expressing ovarian cancer cells via an intracellular anti-erbB-2 single-chain antibody ( $\mathrm{sFv}$ ). This would be achieved by delivery of a gene construct encoding the anti-erbB- $2 \mathrm{sFv}$ directly to tumor cells. The first step in developing this approach was to determine which vector system was capable of achieving the 
highest frequency in situ transduction of ovarian cancer cells. In this regard, previous studies by Crystal (19) and Abelda (20) had demonstrated the utility of recombinant adenoviral vectors in accomplishing gene delivery to human tumor xenografts heterotopically transplanted into the peritoneum of athymic nude mice. In addition, our previous studies using the adenovirus-polylysine vector ( $\operatorname{AdpL})(13,14)$ to accomplish intraperitoneal transduction of a lymphoblastoid cell line in a murine model of B cell lymphoma had demonstrated therapeutic efficacy of this vector (21). Preliminary in vitro studies had also suggested the utility of the cationic liposome vector DOTAP (11). We thus compared the relative efficacy of these vectors in the context of the gene transfer requirements of our strategy.

For this analysis, athymic nude mice were transplanted orthotopically with the human ovarian carcinoma cell line SKOV3.ip1 (22). Xenografting of this cell line had been shown to allow the establishment of a disease model with many of the characteristics of human ovarian carcinoma (22). In addition, this cell line is erbB-2 positive, allowing study of our $\mathrm{sFv}$ mediated cytotoxicity strategy. The athymic nude mice were each transplanted with $10^{7}$ SKOV3. ip1 cells via peritoneal inoculation. $5 \mathrm{~d}$ after transplantation, at which time malignant ascites had been established, the animals were challenged with the various vectors encoding an $E$. coli $\beta$-galactosidase reporter gene ( $\mathrm{LacZ}$ ). Animals thus received the LacZ-encoding adenovirus AdCMVLacZ ( $\left.10^{9} \mathrm{pfu}\right)$, AdpL-DNA complexes containing the LacZ-encoding plasmid $\mathrm{CMV} \beta$ (2.0 $\mu \mathrm{g}$ DNA), or DOTAP-DNA complexes containing the LacZ-encoding plasmid. $2 \mathrm{~d}$ after vector delivery, animals underwent peritoneal lavage to harvest mobile tumor cells for analysis of the erbB-2 oncoprotein and LacZ expression to indicate the specific subset of reporter gene-transduced tumor cells. In this analysis, the recombinant adenovirus accomplished transduction of $>80 \%$ of the malignant ascites tumor cell population (Fig. 1). This transduction frequency was significantly higher than that observed with the other evaluated vector systems. Based upon these results, a gene therapy strategy for ovarian cancer via anti-erbB-2 sFv gene transfer was designed using a recombinant adenovirus as the delivery vehicle.

We have shown previously that an ER-directed antierbB-2 sFv could accomplish specific cytotoxicity in erbB-2overexpressing tumors of diverse histologic types (11). In addition, we have described previously the construction of a recombinant adenoviral vector encoding this gene construct (15). This vector is an E1A-deleted, replication-defective adenovirus derived by standard in vivo homologous recombination techniques. We next sought to demonstrate that the anti-erbB-2 $\mathrm{sFv}$ gene in this vector could function in a manner to achieve the desired tumor cell-specific cytotoxicity. For this analysis, tumor cells were treated in vitro with the adenovirus encoding the ER-directed anti-erbB-2 sFv (Ad21) or an adenovirus encoding the LacZ reporter gene (AdCMVLacZ). Treated cells included the erbB-2-overexpressing ovarian cancer cell line, SKOV3. ip1, as well as the non-erbB-2-expressing human cervical carcinoma cell line HeLa. Adenoviral vector-transduced cells were then examined for viability using the XTT assay as described previously $(11,15)$. In this analysis, it could be seen that the Ad21 vector accomplished a marked reduction in the number of viable SKOV3. ip1 tumor cells (Fig. 2). Using an moi of 50 particles per cell, $>95 \%$ of the SKOV3. ip1 tumor cells were killed. Importantly, this cytotoxicity was selective; no decrement in viable cell number was noted in the nonerbB-2-expressing HeLa cell line treated with the Ad21 vector. This finding is consistent with the concept that the erbB-2 $\mathrm{sFv}$ is selectively cytotoxic in erbB-2-overexpressing tumor cells. This selective cytotoxicity is retained in the context of the antierbB-2 sFv encoding the adenoviral construct. Further in this regard, we have also shown that expression of the antierbB-2 $\mathrm{sFv}$ is nontoxic in a variety of erbB-2-negative human cells of diverse histologic type (data not shown). It is also noteworthy that the control reporter gene encoding adenovirus was noncytotoxic when delivered at the same moi, excluding the possibility of nonspecific vector-associated toxicity.

We next established the capacity of the adenoviral vector encoded anti-erbB-2 sFv to accomplish tumor cell killing in a disease-relevant context. For this analysis, the Ad21 vector was administered to animals which had been orthotopically engrafted with SKOV3. ip1 cells $5 \mathrm{~d}$ previously. $48 \mathrm{~h}$ after vector administration, mobile tumor cells were harvested by peritoneal lavage, and tumor cells were analyzed for the phenotypic effects of the anti-erbB-2 sFv gene transfer and expression. To determine the capacity of the adenoviral vector to accomplish in vivo tumor cell cytotoxicity, in situ lavage-harvested tumor cells were evaluated for cell viability using the XTT assay. In this analysis, it could be seen that the Ad21 vector was capable of marked reduction in the number of viable tumor cells compared with the control vector AdCMVLacZ (Fig. 3 A). Thus, in the context of mobile tumor cells in malignant ascites, the adenoviral vector was capable of achieving in situ transduction with selective tumor cell cytotoxicity. Further in this regard, previous in vitro studies had demonstrated that the basis of the $\mathrm{sFv}$-mediated cytotoxicity was induced apoptosis (11). To determine if this was also the operative mechanism in vivo, harvested tumor cells were analyzed for phenotypic changes indicative of apoptosis. For this analysis, tumor cells from the treatment groups were analyzed for differential nuclear dye staining, a hallmark of cellular apoptosis (23). It was noted that the tumor cells harvested from the AdLacZ-treated animals were viable. In contrast, tumor cells harvested from the Ad21treated animals exhibited dye staining characteristics consistent with induced apoptosis (Fig. $3 B$ ). Thus, the anti-erbB-2 sFvencoding adenoviral vector was capable of induced cytotoxicity in tumor cells based upon selective induction of the apoptosis program.

As a more stringent test of the efficacy of this approach, the ability of the Ad21 vector to reduce an established tumor burden was examined. In this analysis, SKOV3. ip1 tumor cells were established orthotopically as before (22), and animals were treated with the control adenovirus or the adenovirus encoding the anti-erbB-2 sFv. Animals were maintained for 14 $\mathrm{d}$ after treatment, and then harvested for a determination of tumor volume. Animals treated with the control adenoviral vector had extensive tumor burdens. Pathologic evaluation demonstrated large tumor nodules with marked invasion of abdominal viscera (liver, lung, and uterus) (Fig. 4, $A$ and $B$ ). In contrast, animals treated with the Ad21 vector had dramatically decreased tumor burdens (Fig. $4 C$ ) with a reduction in the number and size of residual tumor nests. Tumor cell invasion was not noted in this group. In addition, rare animals in this group were free of tumor by gross and microscopic evaluation. Thus, the 


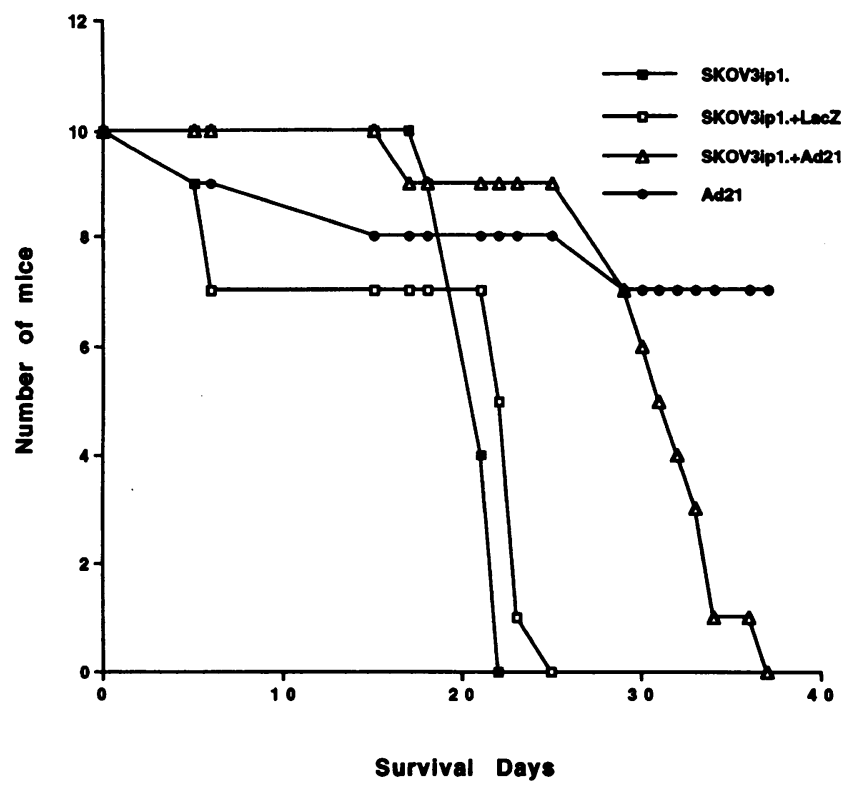

Figure 5. In vivo efficacy of the recombinant adenovirus encoding the ER form anti-erbB-2 sFv in prolongation of survival. erbB-2-overexpressing human ovarian carcinoma cells SKOV3. ip1 were injected intraperitoneally into CB-17 SCID mice $(n=10) .5 \mathrm{~d}$ later the animals were challenged with AdCMVLacZ or Ad21. Animals were assayed for survival.

delivery of the anti-erbB- $2 \mathrm{sFv}$ by this vector approach resulted in a significant antitumor effect.

The ability of the Ad21 vector to modulate survival of ovarian cancer tumor-bearing animals was also evaluated. For these studies, SCID mice were xenografted with the SKOV3. ip1 cells as before. After the establishment of tumor, the animals were treated with either the control or anti-erbB- 2 sFv adenovirus and evaluated for survival. Experimental groups included animals receiving tumor only, tumor followed by control adenovirus infection, or tumor followed by Ad21 infection. The results of this analysis are shown in Fig. 5. Using the log-rank test, significant differences in survival were observed among control groups $(P<0.01)$, compared with the experimental group. The two control groups (cells only and cells plus AdCMVLacZ) had an increased risk of death by 12.4 and 6.4 times, respectively.

\section{Discussion}

The overexpression of the erbB-2 tyrosine kinase receptor has been shown to be a key determinant in neoplastic transformation and progression in a variety of neoplasms including epithelial malignancies of the breast, lung, stomach, and ovary (24-30). Importantly, in carcinoma of the breast and ovary, the overexpression of erbB-2 correlates with a more aggressive tumor phenotype, indicative of a less favorable clinical outcome (26, 28 ). Based upon these concepts, many therapeutic approaches have been developed which target the erbB-2 oncoprotein (31). For example, specific antibody-based approaches have been explored using antitumor erbB-2 antibodies or anti-erbB-2 antibodies conjugated to specific antitumor moieties (32-42).

As an alternate approach to target the erbB-2 oncoprotein, strategies have been developed to directly modulate the levels of the overexpressed tyrosine kinase receptor. These approaches have included triplex-forming oligonucleotides to achieve transcription block, as well as antisense oligonucleotides to target posttranscriptional erbB-2 transcript species $(5,43,44)$. The utility of these approaches has been partially characterized in various in vitro systems. In these studies, it could be shown that downmodulation of cell surface erbB-2 may be achieved with an effect of proliferation inhibition $(32,38,39,41,43$, 44). As an alternate means to achieve knockout of the erbB-2 oncoprotein, we have developed a strategy based upon intracellular expression of the anti-erbB-2 single chain antibody (10). In addition, others have also used the intracellular antibody strategy to achieve functional ablation of the erbB-2 oncoprotein $(45,46)$. We have demonstrated that this approach can achieve cytotoxicity in erbB-2-overexpressing human cells $(11,12)$. It appears that this effect is achieved by virtue of $\mathrm{sFv}$-mediated erbB-2 mislocalization inducing cellular apoptosis (11). Importantly, this antitumor cytotoxicity is targeted in that nonerbB-2-expressing cells do not appear susceptible to the deleterious effects of intracellular anti-erbB-2 $\mathrm{sFv}$ expression.

We have explored the potential of this approach as a gene therapy strategy for ovarian carcinoma. In this regard, erbB-2positive ovarian primary tumor material demonstrated the same sensitivity to anti-erbB- $2 \mathrm{SFv}$ mediated cytotoxicity as we had observed previously in ovarian cancer cell lines (12). Based upon these findings, we have explored the efficacy of this approach in animal models of human ovarian cancer in this report. Our studies demonstrate that adenoviral-mediated delivery of the anti-erbB-2 sFv can accomplish an antitumor effect with a demonstrated survival advantage in treated animals.

One attractive feature of this approach is that the intracellular expression of the anti-erbB-2 sFv is selectively toxic for erbB-2-overexpressing tumors. Thus, the mandate to achieve tumor cell-specific transduction is obviated, as ectopic expression of the anti-erbB-2 $\mathrm{sFv}$, even if it were to occur, is not deleterious. Additionally, in ovarian cancer, where containment of intraperitoneally delivered vector is desired, ectopic expression of the therapeutic gene construct is not a major limitation. Indeed, this has been recognized in other anti-ovarian cancer gene therapies $(19,20)$, whereby vector confinement within the peritoneal cavity has been demonstrated. However, it must be noted that these later proposals are based upon selective delivery of the HSVTk gene. Ectopic Tk gene expression could not be considered without consequence, as its mechanism of cytotoxicity is less dependent upon tumor-specific factors, as is the case within the intracellular antibody strategy.

One potential limitation of this strategy is the requirement to accomplish transduction of all neoplastic cells to achieve tumor eradication. Despite this consideration, we show that a nonoptimized vector delivery dose and schedule achieved tumor reduction at a level capable of accomplishing survival prolongation. These issues will nonetheless be key determinants in the employment of this strategy in the human setting. Thus, it is unclear if antivector immunity will limit the ability to use this vector in repetitive delivery (47). Studies are currently underway to evaluate this issue in other adenoviral delivery schemas. However, it must be noted that vector transduction of all tumor targets may be a theoretical requirement only. In this regard, a greater efficacy of HSVTk gene therapy has been noted in immunocompetent as compared with immunodeficient animals. 
It has been postulated that the Tk-killed tumor fraction functions as an effective vaccine, allowing the enhanced development of an antitumor immunity (48). Further in this regard, Baserga (49) has shown recently that tumor cells treated to achieve IGF1-R knockout function as highly effective antitumor vaccines capable of accomplishing eradication of established syngeneic tumor in rodent models. These studies suggest that apoptotic cells may elicit better antitumor immunization. Considered in this context, the present strategy may likewise allow for antitumor events over and above direct $\mathrm{sFv}$-mediated tumor cell killing.

\section{Acknowledgments}

The authors would like to thank Myung Kim for providing valuable technical assistance. We also acknowledge the expert editorial assistance of Connie Howton.

\section{References}

1. Takahashi, T., D. Carbone, T. Takahashi, M. M. T. Hida, I. Linnoila, R. Ueda, and J. D. Minna. 1992. Wild-type but not mutant p53 suppresses the growth of human lung cancer cells bearing multiple genetic lesions. Cancer Res. 52:23402343.

2. Baker, S. J., S. Markowitz, E. R. Fearon, J. K. V. Willson, and B. Vogelstein. 1990. Suppression of human colorectal carcinoma cell growth by wild-type p53. Science (Wash. DC). 249:912-915.

3. Bookstein, R., J. Shew, P.-L. Chen, P. Scully, and W.-H. Lee. 1990. Suppression of tumorigenicity of human prostate carcinoma cells by replacing the mutated RB gene. Science (Wash. DC). 247:712-715.

4. Huang, H.-J., J.-K. Yee, J.-Y. Shew, P.-L. Chen, R. Bookstein, T. Friedmann, E. Y.-H. P. Lee, and W.-H. Lee. 1988. Suppression of the neoplastic phenotype by replacement of the RB gene in human cancer cells. Science (Wash. DC). 242:1563-1566.

5. Ebbinghaus, S. W., J. E. Gee, B. Rodu, C. A. Mayfield, S. Sanders, and D. M. Miller. 1993. Triplex formation inhibits HER-2/neu transcription in vitro. J. Clin. Invest. 92:2433-2439.

6. Cooney, M., G. Czernuszewicz, E. H. Postel, S. J. Flint, and M. E. Hogan. 1988. Site-specific oligonucleotide binding represses transcription of the human c-myc gene in vitro. Science (Wash. DC). 241:456-459.

7. Rossi, J. J. 1995. Therapeutic antisense and ribozymes. Br. Med. Bull. 51:217-225.

8. Ohta, Y., T. Tone, T. Shitara, T. Funato, L. Jiao, B. I. Kashfian, E. Yoshida, M. Horng, P. Tsai, K. Lauterbach, et al. 1994. H-ras ribozyme-mediated alteration of the human melanoma phenotype. Ann. NY Acad. Sci. 716:242-252.

9. Mukhopadhyay, T., M. Tainsky, A. C. Cavendar, and J. A. Roth. 1991. Specific inhibition of K-ras expression and tumorigenicity of lung cancer cells by antisense RNA. Cancer Res. 51:1744-1748.

10. Deshane, J., F. Loechel, R. M. Conry, G. P. Siegal, C. R. King, and D. T. Curiel. 1994. Intracellular single-chain antibody directed against erbB2 downregulates cell surface erbB2 and exhibits a selective anti-proliferative effect in erbB2 overexpressing cancer cell lines. Gene Ther. 1:332-337.

11. Deshane, J., J. Grim, S. Loechel, G. P. Siegal, R. D. Alvarez, and D. T. Curiel. 1995. Intracellular antibody against erbB-2 mediates targeted tumor cell eradication by apoptosis. Cancer Gene Ther. In press.

12. Deshane, J. G. Cabrera, J. E. Grim, G. P. Siegal, J. Pike, R. D. Alvarez, and D. T. Curiel. 1995. Gynecologic oncology. Gynecol. Oncol. 59:8-14.

13. Curiel, D. T., E. Wagner, M. Cotten, M. L. Birnstiel, S. Agarwal, and C.-M. Li. 1992. High-efficiency gene transfer mediated by adenovirus coupled to DNA-polylysine complexes. Human Gene Therapy. 3:147-154.

14. Curiel, D. T. 1994. High-efficiency gene transfer employing adenoviruspolylysine-DNA complexes. Nat. Immun. 13:141-164.

15. Grim, J., J. Deshane, M. Feng, M. Kay, and D. T. Curiel. 1995. ErbB-2 knockout employing an intracellular single chain antibody (sFv) accomplishes specific toxicity in erbB-2 expressing lung cancer cells. ATS International Conference 1995. Abstract 328725 .

16. Becker, T. C., R. J. Noel, W. S. Coats, A. M. Gomez-Fiox, T. Alam, R. D. Gerard, and C. B. Newgard. 1994. Use of recombinant adenovirus for metabolic engineering of mammalian cells. Methods Cell Biol. 43:161-189.

17. Feng, M., G. Cabrera, J. Deshane, K. J. Scanlon, and D. T. Curiel. 1995. Neoplastic reversion accomplished by high efficiency adenoviral-mediated delivery of an anti-ras ribozyme. Cancer Res. 55:2024-2028.
18. Sobol, R. E., and K. J. Scanlon, editors. Clinical protocols. 1995. Cancer Gene Ther. 2:67-79.

19. Brody, S. L., A. Jaffe, S. K. Han, R. P. Wersto, and R. G. Crystal. 1994. Direct in vivo gene transfer and expression in malignant cells using adenovirus vectors. Human Gene Therapy. 5:437-447.

20. Smythe, W. R., L. R. Kaiser, H. C. Hwang, K. M. Amin, J. M. Pilewski, S. J. Eck, J. M. Wilson, and S. M. Abelda. 1994. Successful adenovirus-mediated gene transfer in an in vivo model of human malignant mesothelioma. Ann. Thorac. Surg. 57:1395-1401.

21. Cook, D. R., I. H. Maxwell, L. M. Glode, F. Maxwell, J. O. Stevens, M. B. Purner, E. Wagner, D. T. Curiel, and T. J. Curiel. 1994. Gene therapy for B-cell lymphoma in a SCID mouse model using an immunoglobulin-regulated diphtheria toxin gene delivered by a novel adenovirus-polylysine conjugate. Cancer Biother. 9:131-141.

22. Yu, D., J. K. Wolf, M. Scanlon, J. E. Price, and M. C. Hung. 1993. Enhanced c-erbB-2/neu expression in human ovarian cancer cells correlates with more severe malignancy that can be suppressed by E1A. Cancer Res. 53:891898.

23. Duke, R. C., and J. J. Cohen. 1992. Morphological and Biochemical Assays of Apoptosis. Current Protocols Supplement 3. K. Janssen, editor. Greene Publishing Assoc. and John Wiley \& Sons, Inc.

24. Hudziak, R. M., J. Schlessinger, and A. Ullrich. 1987. Increased expression of the putative growth factor receptor $\mathrm{p} 185^{\mathrm{HER} 2}$ causes transformation and tumorigenesis of NIH 3T3 cells. Proc. Natl. Acad. Sci. USA. 84:7159-7163.

25. Hynes, N. E. 1993. Amplification and overexpression of the erbB-2 gene in human tumors: its involvement in tumor development, significance as a prognostic factor, and potential as a target for cancer therapy. Cancer Biology. 4:19-26.

26. Slamon, D. J., W. Godolphin, L. A. Jones, J. A. Holt, S. G. Wong, and D. E. Keith. 1989. Studies of the HER-2/neu proto-oncogene in human breast and ovarian cancer. Science (Wash. DC). 244:707-713.

27. Yu, D., S.-S. Wang, K. M. Dulski, C.-M. Tsai, G. L. Nicolson, and M.-C. Hung. 1994. c-erbB-2/neu overexpression enhances metastatic potential of human lung cancer cells by induction of metastasis-associated properties. Cancer Res. 54:3260-3266.

28. Press, M. F., M. C. Pike, G. Hung, J. Y. Zhou, Y. Ma, J. George, J. D. Band, W. James, D. J. Slamon, J. G. Batsakis, and A. K. El-Naggar. 1994. Amplification and overexpression of HER-2/neu in carcinomas of the salivary gland: correlation with poor prognosis. Cancer Res. 54:5675-5682.

29. Noguchi, M., M. Murakami, W. Bennett, R. Lupu, F. Hui, and C. C. Harris. 1993. Biological consequences of overexpression of a transfected c-erbB2 gene in immortalized human bronchial epithelial cells. Cancer Res. 53:20352043.

30. Giovanella, B. C., D. M. Vardeman, L. J. Williams, D. J. Taylor, P. D. De Ipolyi, and P. J. Greeff. 1991. Heterotransplantation of human breast carcinomas in nude mice. Correlation between successful heterotransplants, poor prognosis and amplification of the Her-2/neu oncogene. Int. J. Cancer. 47:66-71.

31. Ishida, T., M. Tsujisaki, Y. Hanzawa, T. Hirakawa, Y. Hinoda, and K. Imai. 1994. Significance of erbB-2 gene product as a target molecule for cancer therapy. Scand. J. Immunol. 39:459-466.

32. Hurwitz, E., I. Stancovski, M. Sela, and Y. Yarden. 1995. Suppression and promotion of tumor growth by monoclonal antibodies to erbB-2 differentially correlate with cellular uptake. Proc. Natl. Acad. Sci. USA. 92:3353-3357.

33. Ishida, T., M. Tsujisaki, Y. Hinoda, K. Imai, and A. Yachi. 1994. Establishment and characterization of mouse-human chimeric monoclonal antibody to the erbB-2 product. Jpn. J. Cancer Res. 85:172-178.

34. Hancock, M. C., B. C. Langton, T. Chan, P. Toy, J. J. Monahan, R. P. Mischak, and L. K. Shawyer. 1991. A monoclonal antibody against the c-erbB-2 protein enhances the cytotoxicity of cis-diamminedichloroplatinum against human breast and ovarian tumor cell lines. Cancer Res. 51:4575-4580.

35. Santes, K. E., D. Slamon, S. K. Andersoin, M. Shepard, B. Fendly, D. Maneval, and O. Press. 1992. Radiolabeled antibody targeting of the HER-2/neu oncoprotein. Cancer Res. 52:1916-1923.

36. Fendly, B. M., M. Winget, R. M. Hudziak, M. T. Lipari, M. A. Napier, and A. Ullrich. 1990. Characterization of murine monoclonal antibodies reactive to either the human epidermal growth factor receptor or HER2/neu gene product. Cancer Res. 50:1550-1558.

37. Fendly, B. M., C. Kotts, D. Vetterlein, G. E. Lewis, M. Winget, M. E. Carver, S. R. Watson, J. Sarup, S. Saks, A. Ullrich, and H. M. Shepard. 1990. The extracellular domain of HER $2 /$ neu is a potential immunogen for active specific immunotherapy of breast cancer. J. Biol. Response Modif. 9:449-455.

38. Drebin, J. A., V. C. Link, D. F. Stern, R. A. Weinberg, and M. I. Greene. 1985. Down-modulation of an oncogene protein product and reversion of the transformed phenotype by monoclonal antibodies. Cell. 41:695-706.

39. Kern, J. A., L. Torney, D. Weiner, A. Gazdar, H. M. Shepard, and B. Fendly. 1993. Inhibition of human lung cancer cell line growth by an anti-p185 18 HER2 antibody. Am. J. Respir. Cell Mol. Biol. 9:448-454.

40. Carter, P., L. Presta, C. M. Gorman, J. B. B. Ridgway, D. Henner, and 
W. L. T. Wong. 1992. Humanization of an anti-p185 ${ }^{\text {HER2 }}$ antibody for human cancer therapy. Proc. Natl. Acad. Sci. USA. 89:4285-4289.

41. Wels, W., I.-M. Harwerth, M. Mueller, B. Groner, and N. E. Hynes. 1992. Selective inhibition of tumor cell growth by a recombinant single-chain antibodytoxin specific for the erbB-2 receptor. Cancer Res. 52:6310-6317.

42. Harwerth, I.-M., W. Wels, B. M. Marte, and N. E. Hynes. 1992. Monoclonal antibodies against the extracellular domain of the erbB-2 receptor function as partial ligand agonists. J. Biol. Chem. 267:15160-15167.

43. Brysch, W., E. Magal, J.-C. Louis, M. Kunst, I. Klinger, and R. Schlingensiepen. 1994. Inhibition of p185c-erbB-2 proto-oncogene expression by antisense oligodeoxynucleotides down-regulates p185-associated tyrosine-kinase activity and strongly inhibits mammary tumor-cell proliferation. Cancer Gene Ther. 1:99105.

44. Bertram, J., M. Killian, W. Brysch, K.-H. Schlingensiepen, and M. Kneba. 1994. Reduction of erbB2 gene product in mammary carcinoma cell lines by
erbB2 mRNA-specific and tyrosine kinase consensus phosphorothioate antisense oligonucleotides. Biochem. Biophys. Res. Commun. 200:661-667.

45. Beerli, R. R., W. Wels, and N. E. Hynes. 1994. Intracellular expression of single chain antibodies reverts erbB-2 transformation. J. Biol. Chem. 269:23931 23936.

46. Graus-Porta, D., R. Beerli, and N. E. Hynes. 1995. Single-chain antibodymediated intracellular retention of erbB-2 impairs Neu differentiation factor and epidermal growth factor signaling. Mol. Cell. Biol. 15:1182-1191.

47. Yei, S., N. Mittereder, K. Tang, C. Sullivan, and B. C. Trapnell. 1994. Adenovirus-mediated gene transfer for cystic fibrosis: quantitative evaluation of repeated in vivo vector administration to the lung. Gene Ther. 1:192-200.

48. Vile, R. G., J. A. Nelson, S. Castleden, H. Chong, and I. R. Hart. 1994 Systemic gene therapy of murine melanoma using tissue specific expression of the HSVtk gene involves an immune component. Cancer Res. 54:6228-6234.

49. Baserga, R. 1994. Oncogenes and the strategy of growth factors. Cell. 79:927-930 